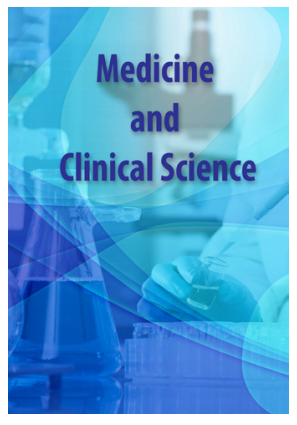

Correspondence

Okacha Naama

Department of Neurosurgery, Military Hospital My Ismail, Meknes, Morocco

E-mail: okacha1972@gmail.com

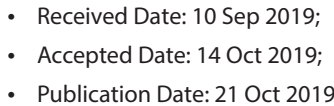

Copyright

(c) 2019 Science Excel. This is an openaccess article distributed under the terms of the Creative Commons Attribution 4.0 International license.

\title{
Occipital lobe ependymal cyst with unusual presentation
}

\author{
Okacha Naama*, Abdelilah Idir, Omar Boulahroud \\ Department of Neurosurgery, Military Hospital My Ismail, Meknes, Morocco
}

\begin{abstract}
Intraparenchymal cysts without communication to the ventricles or the subarachnoid space are named ependymal or epithelial cysts. The estimated ratio of their incidence compared with arachnoid cysts is 1:10. Neurologic deficit can occur when the cyst exerts mass effect on its surroundings. We report a case of cerebral ependymal cyst in a 75-year-old lady who presented with history of headache, vomiting and left incomplete homonymous hemianopsia. Neuroimaging studies showed a large right occipital cyst. She underwent the neurosurgical procedure of marsupialization. Histologic findings and the immunophenotype was consistent with a diagnosis of ependymal cyst. The patient made an excellent recovery after the procedure.
\end{abstract}

\section{Introduction}

Ependymal cysts represent benign congenital ependymal-lined cysts $[1,2]$ and constitute a very rare cause of neurological symptoms among intracranial cystic lesions [3,4]. As term of terminology, they are designed by several synonyms as "ependymal cyst", "neuroepithelial cyst", "glioependymal cyst" and neuroglial cyst" testifying the difficulty of naming this disorder. They are generally located inside the lateral ventricles or in the juxtaventricular regions, particularly the temporoparietal and frontal lobe [2]. They are considered to originate from sequestration of developing neuroectoderm during embryogenesis $[2,5]$. The cysts often occur intracranially in the cerebral parenchyma; however, some cases have been described elsewhere in the cerebral nervous system such as posterior cerebral fossa and spinal cord $[6,7]$. In this article, we report the case of an intracranial ependymal cyst in a 75-year-old woman with intracranial hypertension (ICH) and visual disturbance.

\section{Case Report}

IA 51-year-old female had experienced episodes of dizziness, headaches, and intermittent episodes of vomiting for about 3 years' period and consulted only when her vision reduced especially in the right eye approximately a year before her admission in our department. However, there was no history of seizure. The neurological examination revealed no motor weakness nor sensory disturbances and the deep tendon reflexes were equally normal. The cerebellar functions were intact. However, the ophthalmological examination revealed light perception in the right eye with a large slowly reacting pupil while the acuity was normal in the contralateral left eye 10/10. Fundoscopy revealed bilateral papilledema. The ocular motility, anterior segment and ocular tonus were normal. Magnetic Resonance Imaging (MRI) demonstrated a $6.5 \mathrm{x}$
$4.5 \times 4.0 \mathrm{~cm}$ non-enhancing cystic mass at the right occipito-parietal and has a signal parallel to that of the cerebrospinal fluid (CSF) in both $\mathrm{T} 1$ and $\mathrm{T} 2$ weighted sequences. The patient underwent right occipital craniotomy. The cyst has been approached and was excised through a small right occipital corticotomy. The lesion appeared to be cystic mass with thin membrane, containing watery fluid, CSFlike and its wall was not clearly separated from the brain parenchyma. During surgery, a fenestration of the cyst to the lateral ventricle was done with subtotal removal of the cyst wall. Post operatively, she was well with no seizure and total resolution of headache. Histopathology examination was reported as ependymal cyst. At follow-up appointments, she was asymptomatic and did not require any aspiration.

\section{Discussion}

Intracranial ependymal cysts are rare lesions that occur less frequently than arachnoid cysts $[1,3,4]$. As stated by Friede and Yasargil [8], Zehnder was the first author to describe this entity in 1938. Currently, our search on PubMed find approximately only 40 cases reported in literature [1,3,6-12] (Table 1). Typically, ependymal cysts are neuroepithelial cysts that arise from ectopic rests of primitive neuroglial tissue, and hence, can arise anywhere in the neuraxis but are often located in the central white matter of the temporoparietal and frontal lobes in juxtaventricular regions $[2,5,12]$. In contrast, there were only four patients with cysts in the occipital lobe, one of whom was our patient (Table1).They differ from arachnoid cysts, as they show no communication to the cerebral ventricles or the subarachnoid space. Compared with other benign cysts, they are relatively rare, with an estimated ratio of 1:10 compared with arachnoid cysts. Most of these lesions are diagnosed incidentally [7]. Clinical symptoms usually result from neurologic deficits caused by mass effect of the cyst $[13,14]$. The natural history of these cysts is unknown. Followup examinations usually disclose no clinical or imaging changes in asymptomatic lesions. Suggested

Citation: Naama O. Occipital lobe ependymal cyst with unusual presentation. Med Clin Sci. 2019;1(2):1-3. 


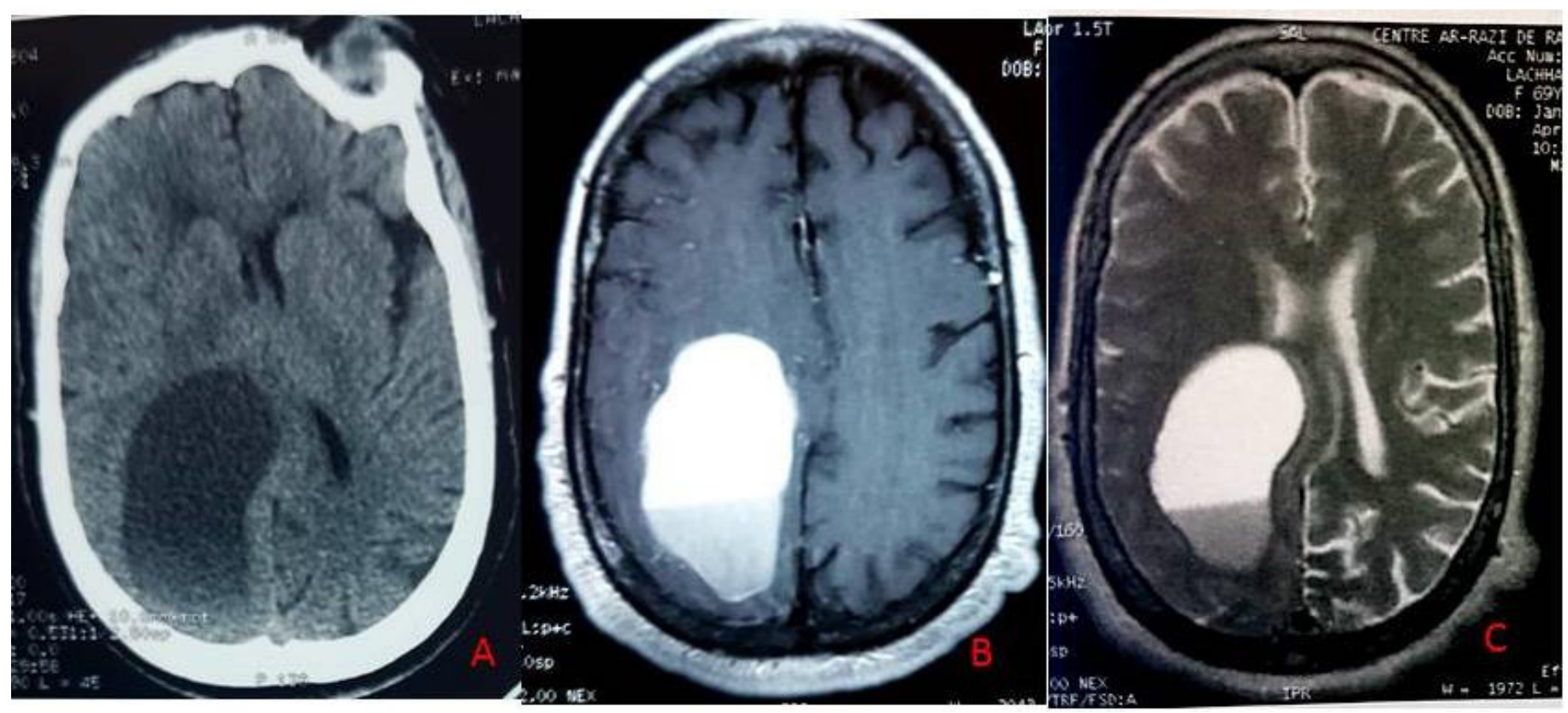

Figure 1. (A) Contrast enhanced CT scan. A non-enhancing low density mass lesion is present in the right occipital region. (B,C) Initial MRI in T1 weighted axiall (B) and T2 weighted axial view showing a large cystic lesion in the occipital lobe with mass effect on the lateral ventricle and adjacent structures. The signal of the lesion is similar to that of CSF, with no enhancement after gadolinium.

\begin{tabular}{|c|c|c|c|c|}
\hline Authors (year) & Cases & Age & Sex & Location \\
\hline Friede \& Yasargil 1977 & 1 & 62 & $\mathrm{~F}$ & Left frontal \\
\hline Friede \& Yasargil 1977 & 2 & 37 & M & Left frontal \\
\hline Ho \& Chason 1987 & 3 & 30 & M & Cerebellopontine, subarachnoid \\
\hline Tsuchidas et al. 1997 & 4 & 29 & M & Cerebellum \\
\hline Boockvar et al. 2000 & 5 & 43 & $\mathrm{M}$ & Lateral ventricle \\
\hline Kanazawa et al. 2000 & 6 & 17 & M & Pineal region \\
\hline Pawar et al. 2001 & 7 & 14 & M & Temporal horn of lateral ventricle \\
\hline Frazier et al. 2004 & 8 & 55 & $\mathrm{~F}$ & Left cerebellum \\
\hline Conrad et al. 2008 & 9 & 35 & $\mathrm{~F}$ & Tectum of the mesencephalon \\
\hline Conrad et al. 2008 & 10 & 53 & $\mathrm{~F}$ & Mesencephalon, pons, left thalamus \\
\hline Conrad et al. 2008 & 11 & 54 & $\mathrm{~F}$ & Mesencephalon \\
\hline Conrad et al. 2008 & 12 & 56 & $\mathrm{~F}$ & Mesencephalon \\
\hline Conrad et al. 2008 & 13 & 60 & $\mathrm{~F}$ & Mesencephalon, thalamus \\
\hline Conrad et al. 2008 & 14 & 35 & $\mathrm{~F}$ & Right mesencephalon, thalamus \\
\hline Conrad et al. 200 & 15 & 36 & M & Left mesencephalon/thalamus \\
\hline Conrad et al. 2008 & 16 & 22 & $\mathrm{~F}$ & Mesencephalon \\
\hline El Damaty et al. 2017 & 17 & 67 & $\mathrm{~F}$ & Right parietal \\
\hline El Damaty et al. 2017 & 18 & 67 & $\mathrm{~F}$ & Right occipital \\
\hline El Damaty et al. 2017 & 19 & 42 & $\mathrm{~F}$ & Midbrain \\
\hline El Damaty et al. 2017 & 20 & 60 & $\mathrm{~F}$ & Left occipital \\
\hline El Damaty et al. 2017 & 21 & 61 & $\mathrm{M}$ & Right parietal \\
\hline El Damaty et al. 2017 & 22 & 65 & $\mathrm{~F}$ & Left frontoparietal \\
\hline Umredkar et al. 2010 & 23 & 25 & $\mathrm{~F}$ & Right frontal \\
\hline Umredkar et al. 2010 & 24 & 25 & $\mathrm{M}$ & Left temporal \\
\hline Gankpé, et al.2019 & 25 & 33 & $\mathrm{~F}$ & Right frontal \\
\hline
\end{tabular}

Friede and Yasargil collected 15 cases described in the literature in 1977 and reported 2 own cases. Adding theses 25 reported cases, it becomes 40 cases.

Table 1. Cases reported on intracranial ependymal cysts since the literature review of Friede \& Yasargil in 1977. 
mechanisms for fluid accumulation within ependymal cysts include active secretion, transcellular transport, and passive transport caused by fluid hyperosmolality $[13,14]$. It is thought that the size of the cyst increases gradually as secretory and breakdown products from the epithelial lining accumulate within it [15]

In terms of radiologic features, ependymal cysts have the same signal as CSF. The best diagnostic clue is a non-enhancing thin-walled CSFcontaining cyst of the lateral ventricle [2]. The differential diagnoses include arachnoid cyst from which it differs as it does not often show any communication with the arachnoid space, the choroid plexus cyst and asymmetrical ventricle. Of importance is our North African setting where hydatid disease is endemic; the ependymal cysts closely resemble a simple brain hydatic cyst. While the anamnesis to point to socioeconomic context and contact with dogs may help in the probability of one diagnosis over the other the neuroradiological characteristics by both the CT and MRI are quite nonspecific to separate the two, hence to keep an open mind in the surgical approach. The role of other diagnostic tests to help to differentiate the two diagnosis can be explored [16]. Various treatment modalities have been suggested over the years.

Conservative follow-up is recommended if the patient is asymptomatic or the symptoms can be managed medically [6,7]. Surgical management is recommended for symptomatic lesions, particularly lesions with mass effect. Surgical approaches have ranged from simple stereotactic aspiration (with or without biopsy) to more invasive procedures such as endoscopic fenestration of the cyst to an adjacent CSF space [7,13,17], placement of an internal cystosubarachnoid or cystoventricular shunt, cyst resection, or open fenestration into the subarachnoid space or ventricles $[7,16,18]$. In our case the cyst wall was resected subtotally and created communication with the lateral ventricle.

\section{Conclusion}

Ependymal cysts are rare congenital cause of neurological deficits among intracranial cysts. It occurs mostly in the supratentorial compartment. Since there is often times a clinico-radiological discordance they are generally incidental findings in majority of cases. While complete surgical excision is the treatment of choice for the symptomatic cysts, cystic fluid diversion presents a better compromise nevertheless in cases where this may not be achieved.

\section{References}

1. Pawar SJ, Sharma RR, Mahapatra AK, et al., Giant ependymal cyst of the temporal horn - an unusual presentation. Case report with review of the literature. Pediatr. Neurosurg. 201; 34: 306-310.

2. Osborn AG, Preece MT. Intracranial cysts: radiologic-pathologic correlation and imaging approach. Radiology. 2006; 239: 650-664.
3. Kanazawa R, Kogure K, Kominami S, et al. Mori, Ependymal cyst producing alpha-fetoprotein Case report. J. Neurosurg 2000; 93: 682685.

4. Harada A, Takeuchi S, Inenaga C, et al., Hemifacial spasm associated with an ependymal cyst in the cerebellopontine angle Case report. J. Neurosurg 2002; 97: 482-485.

5. Tange $\mathrm{Y}$, Aoki A, Mori K, et al., Interhemispheric glioependymal cyst associated with agenesis of the corpus callosum-case report. Neurol Med Chir (Tokyo) 2000; 40: 536-542.

6. Conrad J, Welschehold S, Charalampaki P, et al., Mesencephalic ependymal cysts: treatment under pure endoscopic or endoscopeassisted keyhole conditions. J Neurosurg 2008; 109: 723-728.

7. El Damaty A, Marx S, Fleck S, et al. Neuroendoscopic approach to intracranial ependymal cysts. World Neurosurg 2017; 97: 383-389.

8. Friede RL, Yasargil MG. Supratentorial intracerebral epithelial (ependymal) cysts: review, case reports, and fine structure. J Neurol Neurosurg Psychiatry 1977; 40: 127-137.

9. Boockvar JA, Shafa R, Forman MS, et al. Symptomatic lateral ventricular ependymal cysts: criteria for distinguishing these rare cysts from other symptomatic cysts of the ventricles: case report, Neurosurgery 2000; 46: 1229-1232 (discussion 1232-1223).

10. Ho KL, Chason JL. A glioependymal cyst of the cerebellopontine angle. Immunohistochemical and ultrastructural studies. Acta Neuropathol 1987; 74: 382-388.

11. Frazier J, Garonzik I, Tihan T, et al. Recurrent glioependymal cyst of the posterior fossa: an unusual entity containing mixed glial elementsCase report. J Neuro-Oncol 2004; 68: 13-17.

12. Umredkar A, Mohindra S, Gupta R, et al. Contrasting behavior of glioependymal cysts: a report of two cases and literature review. Neurol India 2010; 58: 659-661.

13. Pant B, Uozumi T, Hirohata $\mathrm{T}$, et al. Endoscopic resection of intraventricular ependymal cyst presenting with psychosis. Surg Neurol. 1996;46:573-576 [discussion: 576-578].

14. Zheng SP, Ju Y, You C. Glioependymal cyst in children: a case report. Clin Neurol Neurosurg 2013; 115: 2288-2290.

15. Obaldo RE, Shao L, Lowe LH. Congenital glioependymal cyst presenting with severe proptosis. AJNR Am J Neuroradiol 2007; 28: 999-1000.

16. Gankpé GF, Ndekha GJ, Naama O, et al. Intracranial ependymal cyst with unusual presentation: Case report and review of literature. Interdisciplinary Neurosurgery 2019; 17: 45-48.

17. Makhoul IR, Zmora O, Tamir A, et al. Congenital subependymal pseudocysts: own data and meta-analysis of the literature, Isr Med Assoc J 2001; 3: 178-183.

18. Uematsu Y, Kubo K, Nishibayashi T, et al. Interhemispheric neuroepithelial cyst associated with agenesis of the corpus callosum. A case report and review of the literature, Pediatr. Neurosurg. 33 (2000) 31-36. 